\title{
Electronic health records in the genomics era: impact of clinical genomics
}

\begin{abstract}
Abbreviations: HER, electronic health records; eMERGE, electronic medical records and genomics; GWAS, genome-wide association studies; NCBI, national center for biotechnology information; NHGRI, national human genome research institute; SNP, single nucleotide polymorphism; PheKB, phenotype knowledge base
\end{abstract}

\section{Editorial}

In 2009 the US Government passed the Health Information Technology for Economic and Clinical Health (HITECH) Act,,${ }^{1,2}$ which reimbursed providers for the meaningful use of a certified Electronic Health Record (EHR). Currently, over $75 \%$ of the officebased physicians in the US are using an EHR system. Parallel efforts are underway in Europe. ${ }^{3}$ Personalized medicine, a long-term goal for healthcare, is beginning to take shape..$^{4-7}$

The human genome project has created a huge opportunity to move personalized genomic-based healthcare to the clinic. ${ }^{8-10}$ This is greatly facilitated by the plummeting cost of DNA sequencing to about $\$ 1,000$ a genome. Just this February, the US Federal Drug Administration approved a direct-to-consumer (DTC) genetic test for Bloom syndrome carrier status ${ }^{11}$ by the company 23 and Me. The 1000 genome project $^{12}$ and more recently the 100,000 Genomes (Genomics England Project) have been generating a large amount of data on genetic variations, the Single Nucleotide Polymorphisms (SNPs) from individuals around the globe. The Genome-Wide Association Studies (GWAS) are beginning to provide valuable clues to risk of disease development and phenotypic association for diverse diseases. ${ }^{13-19}$ The clinical significance of the SNPs is incorporated in the Clinical Variations (ClinVar) database ${ }^{20}$ from the National Center for Biotechnology Information (NCBI).

Basic and translational researchers are well into the post genome era, but the current generations of physicians (with the exception of medical geneticists) are lagging far behind. ${ }^{21,22}$ The Medical schools around the globe have been slow to incorporate modules on clinical genomics. Although use of genetic counselors has been the traditional medical approach, the field of genomics is highly complex and its datasets continuously evolving. Thus, a major gap exists between the advances in the genomics field and the physician interface with patients. ${ }^{23}$ Furthermore, the EHR systems that are in wide use today offer little support for incorporation of genomics data. In a recent survey, only a small percentage of EHR specialists, primary care clinicians, medical geneticists, and genetic counselors surveyed (9\%), felt that the EHR had an impact on genomics medicine. ${ }^{24}$

There is a strong need for incorporating the genomics data into the EHR, if the advances in genetics are to help clinicians make the bestinformed treatment decisions. In the past, genetic information was gathered, and patients counseled about the findings, only in families with a history of a particular disease or disorder. To begin to address this, the Electronic Medical Records and Genomics (eMERGE) Network, a National Human Genome Research Institute (NHGRI)funded consortium was created. The eMERGE Network was tasked

\author{
Volume 2 Issue 3 - 2015
}

\author{
Ramaswamy Narayanan \\ Department of Biological Sciences, Charles E. Schmidt College \\ of Science, Florida Atlantic University, USA
}

\begin{abstract}
Correspondence: Ramaswamy Narayanan, Department of Biological Sciences, Charles E. Schmidt College of Science, Florida Atlantic University, Boca Raton, FL3343I, USA, Tel 56|2972247, Fax 56 2973859, Email rnarayan@fau.edu
\end{abstract}

Received: March 29, 2015 | Published: April 06, 2015

with developing methods and best practices for the utilization of the EHR as a tool for genomic research. ${ }^{25-27}$ The network currently incorporates nine geographically distinct groups around the US. The initial focus of the eMERGE phenotypes included cataract and High Density Lipoprotein (HDL), dementia, electrocardiographic QRS duration, peripheral arterial disease, type 2 diabetes and hypothyroidism. ${ }^{27}$ The eMERGE is now in its sixth year and second funding cycle (eMERGE II) and continues to make advances in the field of genomics and health-care informatics. The first cycle of eMERGE had three major aims: (i) use EHR data for electronic phenotyping, (ii) conduct GWAS using the phenotypes and (iii) explore the ethical, legal, and social implications (ELSI) associated with EHR-based GWAS and wide-scale data sharing. ${ }^{25}$ A Phenotype KnowledgeBase (PheKB) effort was created to develop phenotypic algorithms across the eMERGE network to facilitate mining the largescale data.

Integration of the genomics data into the EHR system faces considerable hurdles. ${ }^{28-30}$ At the present time, no commercial EHR system is available that incorporates genomic data. Furthermore, the pharmacogenetic information, which could have a major impact in reducing adverse drug effects and efficacy, is still rarely used. This is despite strong evidence for clinical validity and utility for the pharmacogenetics use in the clinic. ${ }^{31-33}$

Other challenges for integration include the amount of the big data the GWAS studies generate (in terabytes), the rapidly expanding SNP variations dataset and the difficulty of establishing meaningful interpretations from these vast amounts of genetic data. The Version 1.0 of the eMERGE data encompassed more than 13million SNPs from 42,000 samples.$^{26}$ In addition, there are a variety of EHR systems becoming available and a standard for handling the vast genomics information is lacking.

The genomics dataset exists in different platforms; system integration and compatibility standards for EHR soft ware are needed. Basic research is still trying to make sense of the mountain of SNP variants emerging from the GWAS results. In this perspective the reluctance shown by the clinicians is understandable. Considerable research still needs to be done to convert the vast amount of genomic data to a succinct distillate for the clinicians. ${ }^{34}$ 
Within a decade the EHR system is projected to change the way medicine is practiced around the globe. In the post genome era we are in, the benefits of the human genome project are beginning to reach the bedside. FDA labeling is starting to incorporate pharmacogenomics information for certain drugs targeted for cardiology, dental, dermatology, gastroenterology, hematology, infections, oncology, neurology and psychiatry.

However, a major gap exists between the vast amount of emerging genetic information and the training needed to translate these findings into bedside-based clinical reality. Training of the current and the future generations of physicians and other healthcare providers in the emerging genomics technology will be crucial. Medical schools around the globe need to embrace such training as a core part of the medical education curriculum.

\section{Acknowledgements}

I thank Jeanine Narayanan for editorial assistance. This work was supported in part by the Genomics of Cancer Fund, Florida Atlantic University Foundation.

\section{Conflict of interest}

The author declares no conflict of interest.

\section{References}

1. Centers for Medicare \& Medicaid Services (CMS), HHS. Medicare and Medicaid programs; electronic health record incentive program. Final rule. Fed regist. 2010;75(144):44313-44588.

2. Centers for Medicare \& Medicaid Services (CMS), HHS. Medicare and Medicaid programs; electronic health record incentive program — stage 2. Final rule. Fed regist. 2012;77(171):53967-54162.

3. Kierkegaard P. Electronic health record: Wiring Europe's healthcare Computer Law \& Security Review. 2011;27(5):503-515.

4. Conti R, Veenstra DL, Armstrong K, et al. Personalized medicine and genomics: challenges and opportunities in assessing effectiveness, cost-effectiveness, and future research priorities. Med Decis Making. 2010;30(3):328-340.

5. Crews KR, Hicks JK, Pui CH, et al. Pharmacogenomics and individualized medicine: translating science into practice. Clin Pharmacol Ther. 2012;92(4):467-475.

6. Moreira AL, Eng J. Personalized therapy for lung cancer. Chest. 2014;146(6):1649-1657.

7. Lazaridis KN, McAllister TM, Babovic-Vuksanovic D, et al. Implementing individualized medicine into the medical practice. $\mathrm{Am} \mathrm{J}$ Med Genet C Semin Med Genet. 2014;166C(1):15-23.

8. Burton H, Cole T, Lucassen AM. Genomic medicine: challenges and opportunities for physicians. Clin Med. 2012;12(5):416-419.

9. Choi IY, Kim TM, Kim MS, et al. Perspectives on clinical informatics: integrating large-scale clinical, genomic, and health information for clinical care. Genomics Inform. 2013;11(4):186-190.

10. Sanz F, Diaz C, Martin-Sanchez F, et al. Structuring European biomedical informatics to support individualized healthcare: current issues and future trends. Stud Health Technol Inform. 2004;107(Pt 2):803-807.

11. Sanz MM, German J. Bloom's Syndrome. In: Pagon RA, et al. editors. Gene Reviews(R). Seattle (WA); 1993.

12. Durbin RM. 1000 Genome Project Consortium, A map of human genome variation from population-scale sequencing. Nature. 2010;467(7319):1061-1073.
13. Simon-Sanchez J, Singleton A. Genome-wide association studies in neurological disorders. Lancet Neurol. 2008;7(11):1067-1072.

14. Denny JC, Bastarache L, Ritchie MD, et al. Systematic comparison of phenome-wide association study of electronic medical record data and genome-wide association study data. Nat Biotechnol. 2013;31(12):11021110 .

15. Pathak J, Kho AN, Denny JC. Electronic health records-driven phenotyping: challenges, recent advances, and perspectives. $J$ Am Med Inform Assoc. 2013;20(e2):e206-e211.

16. Postmus I, Trompet S, Deshmukh HA, et al. Pharmacogenetic metaanalysis of genome-wide association studies of LDL cholesterol response to statins. Nat commun. 2014;5:5068.

17. Hirokawa M, Morita H, Tajima T, et al. A genome-wide association study identifies PLCL2 and AP3D1-DOT1L-SF3A2 as new susceptibility loci for myocardial infarction in Japanese. Eur J Hum Genet. 2015;23(3):374 380 .

18. Wolpin BM, Rizzato C, Kraft P, et al. Genome-wide association study identifies multiple susceptibility loci for pancreatic cancer. Nat Genet 2014;46(9):994-1000.

19. Shungin D, Winkler TW, Croteau-Chonka DC, et al. New genetic loci link adipose and insulin biology to body fat distribution. Nature. 2015;518(7538):187-196.

20. Landrum MJ, Lee JM, Riley GR, et al. ClinVar: public archive of relationships among sequence variation and human phenotype. Nucleic Acids Res. 2014;42(Database issue):D980-985.

21. Salari K. The dawning era of personalized medicine exposes a gap in medical education. PLoS Med. 2009;6(8):e1000138.

22. Guttmacher AE, Porteous ME, McInerney JD. Educating healthcare professionals about genetics and genomics. Nat Rev Genet. 2007;8(2):151-157.

23. Belmont J, McGuire AL. The futility of genomic counseling: essential role of electronic health records. Genome Med. 2009;1(5):48.

24. Ury AG. Storing and interpreting genomic information in widely deployed electronic health record systems. Genet Medicine. 2013;15(10):779-785.

25. Kho AN, Pacheco JA, Peissig PL, et al. Electronic medical records for genetic research: results of the eMERGE consortium. Sci Transl Med. 2011;3(79):79re1.

26. Gottesman O, Kuivaniemi H, Tromp G, et al. The Electronic Medical Records and Genomics (eMERGE) Network: past, present, and future. Genet Med. 2013;15(10):761-771.

27. McCarty CA, Chisholm RL, Chute CG, et al. The eMERGE Network: a consortium of biorepositories linked to electronic medical records data for conducting genomic studies. BMC Med Genomics. 2011;4:13.

28. Kannry JM, Williams MS. Integration of genomics into the electronic health record: mapping terra incognita. Genet Med. 2013;15(10):757760 .

29. Farrugia G, Weinshilboum RM. Challenges in implementing genomic medicine: the Mayo Clinic Center for Individualized Medicine. Clin Pharmacol Ther. 2013;94(2):204-206.

30. Kho AN, Rasmussen LV, Connolly JJ, et al. Practical challenges in integrating genomic data into the electronic health record. Genet Med. 2013;15(10):772-778.

31. Mrazek DA, Lerman C. Facilitating clinical implementation of pharmacogenomics. JAMA. 2011;306(3):304-305.

32. Roden DM, Xu H, Denny JC, et al. Electronic medical records as a tool in clinical pharmacology: opportunities and challenges. Clin Pharmacol Ther. 2012;91(6):1083-1086. 
33. Pacanowski MA, Leptak C, Zineh I. Next-generation medicines: past regulatory experience and considerations for the future. Clin Pharmacol Ther. 2014;95(3):247-249.
34. Marsolo K, Spooner SA. Clinical genomics in the world of the electronic health record. Genet Med. 2013;15(10):786-791. 